\title{
Sub-Par Performance In A Sub-Prime World? A Recent Comparative Performance Analysis Of Real Estate Mutual Funds Vs. Common Stock Mutual Funds
}

James L. Kuhle, Ph.D., California State University, Sacramento, USA

Rafiqul Bhuyan, Ph.D., California State University, San Bernardino, USA

\begin{abstract}
Historically, little evidence has been found to suggest that real estate investments exhibit superior returns. Further, it appears that real estate mutual fund managers do not possess the ability to consistently beat benchmark averages. However, there have been mixed results for REITs indicating they might be characterized by inefficiencies that could be exploited by informed fund managers. In this analysis, we examine whether mutual fund managers who have concentrated in real estate assets have statistically outperformed other categories of equity mutual funds as well as the $S \& P 500$ and various NAREIT Indexes.
\end{abstract}

Keywords: REITs, REIT Performance, Real Estate Mutual Funds, Real Estate Mutual Fund Performance

\section{INTRODUCTION AND PURPOSE}

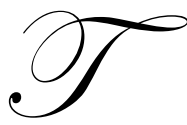

he sub-prime crisis of 2008 has led to significant reductions in returns of all major assets within the U.S. financial system. But even for 18 months prior to the toxic debt revelations, financial instruments and particularly mutual funds have suffered from less than stellar return performance. The real estate market has been especially hard hit. Once housing prices started to drop moderately in 2006-2007 in many parts of the U.S., refinancing became more difficult. Defaults and foreclosures increased dramatically as Adjustable Rate Mortgage (ARM) interest rates reset higher. During 2007, nearly 1.3 million U.S. housing properties were subject to foreclosure, up 79\% from 2006. The purpose of this research is to examine the risk/return performance of real estate mutual funds when compared to common stock mutual funds. This is done by analyzing risk-adjusted returns for seven different mutual fund categories, including real estate mutual funds. Various time horizons are examined including the most recent year to date, annual, three year, five year, and ten year periods.

\section{LITERATURE REVIEW}

Historic mutual fund performance has been a topic among many academics, with most researchers concentrating on equity mutual funds. In the seminal study of mutual fund performance, Jensen (1968) developd the risk-adjusted Jensen alpha and found that equity funds tend to exhibit negative risk-adjusted performance on average over a period of 1945-64. Elton, Gruber, Das and Hlavka (1993) examined mutual fund returns over the 1965-84 period and also found negative average performance. Further, they found that equity fund performance was negatively related to the magnitude of expense ratios and the level of portfolio trading measured by turnover.

Carhart (1997) further explored the persistence in mutual fund performance originally documented by Hendricks, Patel and Zeckhauser (1993) and Elton, Gruber, Das and Blake (1996). With a sample of equity mutual 
funds from the period 1962-93, Carhart found that most of the persistence in performance was concentrated in poor performers. It was concluded that poor performing funds tend to continue performing poorly. Carhart further reaffirmed a negative relationship between performance and expense ratios and fund turnover. The superior performance of real estate assets has been debated over the last twenty plus years. Kuhle, Walther and Wurtzebach (1986), Titman and Warga (1986), Goebel and Kim (1989), Chan, Hendershott and Sanders (1990), Glascock (1991) and Martin and Cook (1991) all focused on the performance of REITs relative to other publicly traded investments. Using a variety of performance measures, these studies find little or no evidence of superior performance for REITs over other common stock investments. Myer and Webb (1993) examined the distributional and time-series properties of equity REIT returns compared to common stock, closed-end stock funds and unsecuritized commercial real estate. They found that equity REIT returns are more similar to those of common stocks and closed-end funds than those returns on unsecuritized real estate. Jarl G. Kallberg, Crocker L. Liu, and Charles Trzcinka (2000), found that contrary to the majority of mutual fund studies, the average and median alphas for real estate mutual funds are positive. Further, it is found that time-varying positive alphas are much more likely to occur when the real asset market is performing poorly, suggesting that managers add more value in down markets than in up markets.

The mispricing of real estate assets due to the characteristics of the real estate asset has been a bane for fairly pricing real estate funds. Redding (2006) examined the TIAA Real Estate Account for mispricing problems among real estate mutual funds. Redding concludes that real estate fund managers face a challenge computing daily NAVs given the large holdings of real estate, for which daily valuations are not practical. The resulting return predictability means that some fund investors profit at the expense of other shareholders. In this particular study, it was found that some long-term investors have suffered a loss, which can be roughly estimated as one quarter percentage point annually due to inaccurately calculated portfolio values. Managers of real estate funds can alleviate this problem by using information in recent property appraisals to update the carrying value of all properties in the portfolios.

Finally, Lin and Young (2007), examine the role that manager style plays in the overall performance of real estate mutual funds. Their sample period covers a time frame from January 1, 1997 to December 31, 2004. The sample covers all real estate mutual funds with at least 24 months of daily return data, as reported by Morningstar, Inc. Their findings suggest that real estate funds are unable to time the style factors defined by the authors. Their analysis suggests that real estate mutual fund investment styles provide insight regarding the kind of product offered and the findings are useful in evaluating real estate mutual fund performance. They conclude that real estate mutual funds tend to be similar to large growth funds and tend to be more representitave of growth mutual funds over value oriented mutual funds.

\section{SAMPLE AND RESEARCH DESIGN}

The sample for this research consists of 249 mutual funds that are provided by Morningstar Inc. and were randomly selected from the Morningstar data base. The selected funds fell into one of seven category classifications including REIT's, Large Value, Small Value, Small Growth, Technology, Health Care and Natural Resources. The REIT mutual fund category is composed of 66 mutual funds that invest only in REITs. Mean, ex-post returns along with variance and standard deviations were calculated to provide statistical data for comparative purposes. These statistical data were then used to calculate Z-scores to compare relative performance differences among the seven categories. In addition, the results of the statistical analysis were also compared to the S\&P 500 Index and the Dow Jones REIT Composite index. Further, return and comparative statistics were calculated for five different time periods. These periods include the most recent 9-month period, 1-year results, 3-year results, 5-year results, and 10year results. As a result, the time periods analyzed include most of the recent downturn in the market due to the sub-prime mortgage crisis and the recently announced trillion dollar Federal Government bailout.

Table 1 provides the year to date returns, standard deviations, and the risk-adjusted factors for the seven mutual fund categories. The year to date time frame covers the period from January through September, 2008. The risk-adjusted factors are determined by dividing the standard deviation by the average returns. Notice that the REIT mutual fund category has the smallest risk-adjusted factor. The risk-adjusted factor essentially standardizes the return for the amount of risk which in this case is measured by the standard deviation. Based on the risk-adjusted statistical measure, the REIT mutual fund category outperforms all other categories. Even though the returns are 
negative, the REIT category has the smallest negative return once adjusted for the magnitude of the standard deviation of those returns (-.082). The Technology category ranks second with a risk-adjusted factor of -.112 while the Small Value category ranks third with a risk-adjusted factor of -.1298.

Table 1

Year to Date Returns, Standard Deviation and Risk-Adjusted Returns Among the Seven Mutual Fund Categories

\begin{tabular}{|l|c|c|c|}
\hline & Average Returns & Standard Deviation & Risk-Adjusted Factor \\
\hline REITs & -30.9495 & 2.5262 & -0.0816 \\
\hline Large Value & -35.7610 & 5.7711 & -0.1614 \\
\hline Small Value & -22.7907 & 3.9912 & -0.1751 \\
\hline Small Growth & -31.6853 & 4.2226 & -0.1298 \\
\hline Technology & -36.5388 & 4.0981 & -0.1122 \\
\hline Health Care & -23.9804 & 5.4145 & -0.2258 \\
\hline Natural Resources & -39.9121 & 8.8694 & -0.2222 \\
\hline S\&P 500 Index & -38.1500 & & \\
\hline DJ REIT Composite & -32.7435 & & \\
\hline
\end{tabular}

Table 2

Year to Date Z-Scores Among The Seven Mutual Fund Categories

\begin{tabular}{|l|c|c|c|c|c|c|c|}
\hline & REIT'S & Large Value & Small Value & Small Grwth & Technology & Health Care & Natural Res. \\
\hline REIT'S (66) & & -0.3248019 & 16.2737935 & 10.3391042 & -6.8206657 & 13.4679897 & -23.06387275 \\
\hline Large Value (50) & 9.995713 & & 22.3468726 & 1.71282854 & -8.7326444 & 7.9738908 & -21.90473429 \\
\hline Small Value (30) & 4.416197 & -14.930915 & & -7.10964084 & -18.046363 & -24.201113 & -28.23410821 \\
\hline Small Growth (42) & 12.93885 & -6.786105 & 10.4878539 & & -9.1670736 & 8.37431889 & -23.44467638 \\
\hline Technology (17) & 4.135607 & -7.3500196 & 6.85706333 & -1.78510171 & & 5.14153042 & 19.63297352 \\
\hline Health Care (50) & -1.93361 & -14.333281 & -0.10432884 & -8.67881337 & -17.426124 & & -27.71281391 \\
\hline Natural Res. (24) & 4.879028 & -15.663385 & -2.33969307 & -11.7870212 & -17.214110 & -3.6763910 & \\
\hline
\end{tabular}

Table 2 provides the $\mathrm{Z}$ scores for the seven different mutual fund categories. The first column represents REIT funds versus the other six fund categories. The $\mathrm{Z}$ score measures the probability that the mean returns between two samples of return data is significantly different from one another. In column one (the REITs column of Table 2), the comparison is made between the mean return data of the REIT category vs. each of the other mutual fund categories. For example, when the comparison is made between REITs and the Large Value category, the calculated $\mathrm{Z}$ score is statistically significant with a value of 9.995713 . Since, by definition, the critical $\mathrm{Z}$ value is \pm 2.33 at a confidence level of .01, it is evident that the returns of the REIT category is significantly less negative than that of the Large Value category. Further, it can be seen from Table 2 that the REIT category is significantly less negative than every other mutual fund category except the Health Care category. However, given the value of the $\mathrm{Z}$ score at -1.93361 , the level of significance is not significant because the $\mathrm{Z}$ score is not less than the critical value of 2.33 .

Table 3

One Year Returns, Standard Deviation and Risk-Adjusted Returns Among the Seven Mutual Fund Categories

\begin{tabular}{|l|c|c|c|}
\hline & Average Returns & Standard Deviation & Risk-Adjusted Factor \\
\hline REITs & -37.9405 & 2.4501 & -0.0646 \\
\hline Large Value & -37.9784 & 5.9714 & -0.1572 \\
\hline Small Value & -22.7907 & 3.9912 & -0.1751 \\
\hline Small Growth & -31.6853 & 4.2226 & -0.1333 \\
\hline Technology & -36.5388 & 4.0981 & -0.1122 \\
\hline Health Care & -23.9804 & 5.4349 & 0.2322 \\
\hline Natural Resources & -39.9121 & 8.8694 & -0.2222 \\
\hline S\&P 500 Index & -40.2400 & & \\
\hline DJ REIT Composite & -41.5300 & & \\
\hline
\end{tabular}

Table 3 provides the calculated returns, standard deviations, and the risk-adjusted factors for the seven mutual fund categories. Again, notice that the REIT mutual fund category has the smallest risk-adjusted factor. 
Based on the risk-adjusted statistical measure, the REIT mutual fund category outperforms all other categories. Even though the returns are negative, the REIT category consistently has the smallest negative return once adjusted for the magnitude of the standard deviation of those returns. The Technology category ranks second with a riskadjusted factor of -.1122 while the Small Growth category ranks third with a risk-adjusted factor of -.1333.

Table 4

One Year Z-Scores Among The Seven Mutual Fund Categories

\begin{tabular}{|l|c|c|c|c|c|c|c|}
\hline & REIT'S & Large Value & Small Value & Small Grwth & Technology & Health Care & Natural Res. \\
\hline REIT'S (66) & & 4.3319088 & 25.3182311 & 11.1837554 & -6.8206657 & 13.4679897 & -23.06387275 \\
\hline Large Value (50) & 4.412074 & & 22.3662887 & 2.55747971 & -8.7326444 & 7.9738908 & -21.90473429 \\
\hline Small Value (30) & -2.32793 & -17.545896 & & -6.26498968 & -18.046363 & -24.201113 & -28.23410821 \\
\hline Small Growth (42) & -6.19144 & -10.268189 & 9.62376661 & & -9.8777892 & 7.53421896 & -23.44467638 \\
\hline Technology (17) & -2.76222 & -9.963010 & 6.85706333 & -0.94045055 & & 5.14153042 & 19.63297352 \\
\hline Health Care (50) & -9.59194 & -17.480503 & $-0 . .6910939$ & -7.83416221 & -17.426124 & & -27.71281391 \\
\hline Natural Res. (24) & 16.19477 & -17.999581 & -2.33969307 & -10.9423701 & -17.21411 & -3.676391 & \\
\hline
\end{tabular}

Table 4 provides the $\mathrm{Z}$ scores for the seven different mutual fund categories and the one year time horizon. The $\mathrm{Z}$ score measures the probability that the mean returns between two samples of return data is significantly different from one another. In column one, the comparison is made between the mean return data of the REIT category vs. each of the other mutual fund categories. For example, when the comparison is made between REITs and the Large Value category, the calculated $\mathrm{Z}$ score is statistically significant with a value of 4.412074. Further, it can also be determined from Table $4, \mathrm{Z}$ scores, the REIT category is significantly more negative than every other mutual fund category except the Large Value and Natural Resource categories. The $\mathrm{Z}$ scores indicate that there is a statistical difference between the returns of the REIT category and four of the remaining six categories.

Table 5

Three Year Returns, Standard Deviation and Risk-Adjusted Returns Among the Seven Mutual Fund Categories

\begin{tabular}{|l|c|c|c|}
\hline & Average Returns & Standard Deviation & Risk-Adjusted Factor \\
\hline REITs & -4.7020 & 1.7946 & -0.3817 \\
\hline Large Value & -5.8740 & 2.8743 & -0.4893 \\
\hline Small Value & -3.8500 & 2.1360 & -1.8024 \\
\hline Small Growth & -2.7000 & 3.0260 & -0.8923 \\
\hline Technology & -5.7241 & 3.0540 & -0.5335 \\
\hline Health Care & -2.1578 & 2.7390 & -1.2693 \\
\hline Natural Resources & +.3800 & 2.2976 & +0.1654 \\
\hline S\&P 500 Index & -8.3500 & & \\
\hline DJ REIT Composite & -16.080 & & \\
\hline
\end{tabular}

Table 5 provides the calculated returns, standard deviations, and the risk-adjusted factors for the seven mutual fund categories for the three year return period. Notice that the Natural resources category has the only positive return at $.38 \%$, while all other categories are negative. Among the remaining six categories with negative returns, the REIT category has the smallest risk-adjusted factor with a value of -..3817.

Table 6

Three Year Z-Scores Among The Seven Mutual Fund Categories

\begin{tabular}{|l|c|c|c|c|c|c|c|}
\hline & REIT'S & Large Value & Small Value & Small Grwth & Technology & Health Care & Natural Res. \\
\hline REIT'S (66) & & 4.28957511 & 8.42093676 & 7.03288828 & 0.3591528 & 13.4679897 & -23.06387275 \\
\hline Large Value (50) & 7.994903 & & 11.03586190 & 7.41842074 & 1.2281138 & 7.9738908 & -21.90473429 \\
\hline Small Value (30) & -0.82938 & -2.1992745 & & 1.55185484 & -3.2512576 & -24.201113 & -28.23410821 \\
\hline Small Growth (42) & -0.69456 & -2.8560573 & 1.33260250 & & -3.3512576 & 7.53421896 & -23.44467638 \\
\hline Technology (17) & 2.703603 & -0.9007986 & 4.76806631 & 4.46741893 & & 5.14153042 & 19.63297352 \\
\hline Health Care (50) & 0.137051 & -2.0310316 & 1.85570274 & 1.48674520 & -3.1426090 & & -27.71281391 \\
\hline Natural Res. (24) & -5.436000 & -6.4862753 & -2.69300096 & -2.64419569 & -6.1575477 & -3.676391 & \\
\hline
\end{tabular}

Table 6 provides the $\mathrm{Z}$ scores for the seven different mutual fund categories over the three year time horizon. In column one, the comparison is made between the mean return data of the REIT category vs. each of the 
other mutual fund categories. The results of this table indicates that the REIT fund category outperforms the Large Value fund category with a Z-score of 7.9949. However, the REIT fund category underperforms against the Small Value and Small Growth categories by a small margin. The REIT fund category significantly underperforms the Natural Resource category with a Z-score of -5.436 . However, the REIT fund category outperforms the Technology and Health Care categories with Z-score values of 2.7036 and .1370 respectively.

Table 7

Five Year Returns, Standard Deviation and Risk-Adjusted Returns Among the Seven Mutual Fund Categories

\begin{tabular}{|l|c|c|c|}
\hline & Average Returns & Standard Deviation & Risk-Adjusted Factor \\
\hline REITs & 5.6167 & 1.5130 & 0.2694 \\
\hline Large Value & 1.1713 & 2.0471 & 1.7477 \\
\hline Small Value & 4.3900 & 1.5180 & 0.3458 \\
\hline Small Growth & 1.9800 & 2.1180 & 1.0697 \\
\hline Technology & -2.8413 & 2.3473 & -0.8261 \\
\hline Health Care & 3.3913 & 2.7455 & 0.8096 \\
\hline Natural Resources & 13.4000 & 2.6875 & 0.2006 \\
\hline S\&P 500 Index & -2.5600 & & \\
\hline DJ REIT Composite & -2.8100 & & \\
\hline
\end{tabular}

Table 7 provides the average returns, standard deviations, and the risk-adjusted factors for the seven mutual fund categories for the five year return period. Notice that the Natural resources category has the largest positive return at $13.4 \%$, while the REIT mutual fund catergory comes in second at $5.62 \%$. However, as we consider riskadjusted return factors notice that the REIT category has the second lowest factor at .2694. The natural resources category has the lowest with a factor of .2006. Again, these values reveal that the REIT mutual fund category compares favorably to the other fund categories as well as the S\&P 500 Index and the Dow Jones REIT Composite Index.

Table 8

Five Year Z-Scores Among The Seven Mutual Fund Categories

\begin{tabular}{|l|c|c|c|c|c|c|c|}
\hline & REIT'S & Large Value & Small Value & Small Grwth & Technology & Health Care & Natural Res. \\
\hline REIT'S (66) & & -15.14523 & -12.43105 & -12.95190 & -12.21843 & -9.65182 & 3.70491 \\
\hline Large Value (50) & 2.21406 & & .88215 & -.70277 & -4.67528 & .97282 & 11.51168 \\
\hline Small Value (30) & -9.83005 & -9.78238 & & -8.93808 & -9.77470 & 4.06726 & 6.25735 \\
\hline Small Growth (42) & 0.35290 & -2.92760 & -.23069 & & -5.85764 & -.51017 & 10.29925 \\
\hline Technology (17) & 10.36031 & 5.62009 & 8.87747 & 6.30846 & & 7.51454 & 17.72232 \\
\hline Health Care (50) & -2.25844 & -5.83075 & -2.71895 & -4.70217 & -7.76265 & & 8.35414 \\
\hline Natural Res. (24) & 17.51330 & -20.43159 & -17.41217 & -19.00489 & -19.79063 & -16.54668 & \\
\hline
\end{tabular}

Table 8 provides the $\mathrm{Z}$ scores for the seven different mutual fund categories for the five year time horizon. In column one, the comparison is made between the mean return data of the REIT category vs. each of the other mutual fund categories. The results of this table indicate that the REIT fund category outperforms the Large Value fund category with a Z-score of 2.21406. However, the REIT fund category underperforms against the Small Value and the Health Care categories with a $\mathrm{Z}$ score of -9.83 and -2.258 respectively. In addition, the REIT fund category outperforms all the remaining fund categories with positive Z-score values.

Table 9

Ten Year Returns, Standard Deviation and Risk-Adjusted Returns Among the Seven Mutual Fund Categories

\begin{tabular}{|l|c|c|c|}
\hline & Average Returns & Standard Deviation & Risk-Adjusted Factor \\
\hline REITs & 13.7970 & 1.7367 & 0.1259 \\
\hline Large Value & 5.8472 & 2.1739 & 0.3718 \\
\hline Small Value & 11.0000 & 1.0601 & 0.0964 \\
\hline Small Growth & 8.4800 & 2.7000 & 0.3184 \\
\hline Technology & 3.9567 & 3.6514 & 0.9228 \\
\hline Health Care & 9.3721 & 1.7951 & 0.1915 \\
\hline Natural Resources & 15.2200 & 2.7851 & 0.1830 \\
\hline S\&P 500 Index & 1.3800 & & \\
\hline DJ REIT Composite & 5.9100 & & \\
\hline
\end{tabular}


Table 9 provides the average returns, standard deviations, and the risk-adjusted factors for the seven mutual fund categories for the ten year return period. Notice that the REIT mutual fund category has the second largest positive return at $13.8 \%$, while the Natural Resources mutual fund catergory comes in first at $15.2 \%$. However, as we consider risk-adjusted return factors notice that the REIT category has the second lowest factor at .1259. The small value category has the lowest with a factor of .0964. Again, these values reveal that the REIT mutual fund category compares favorably to the other fund categories as well as the S\&P 500 Index and the Dow Jones REIT Composite Index.

Table 10

Ten Year Z-Scores Among The Seven Mutual Fund Categories

\begin{tabular}{|l|c|c|c|c|c|c|c|}
\hline & REIT'S & Large Value & Small Value & Small Grwth & Technology & Health Care & Natural Res. \\
\hline REIT'S (66) & & -30.99846 & -36.84420 & -20.98420 & -11.18769 & -32.19973 & -7.49598 \\
\hline Large Value (50) & 21.23038 & & -9.27648 & -2.81299 & -2.28071 & -5.29343 & 6.17294 \\
\hline Small Value (30) & 10.71222 & -24.43192 & & -16.09655 & -8.17791 & -9.84508 & -3.09656 \\
\hline Small Growth (42) & 11.35473 & -8.74928 & -7.45958 & & -4.70787 & -8.00951 & 3.18855 \\
\hline Technology (17) & 10.80128 & 1.62645 & 6.63518 & 4.43717 & & 5.07723 & 10.27661 \\
\hline Health Care (50) & 13.33270 & -18.35841 & -18.35841 & -10.73016 & -6.21640 & & 0.16715 \\
\hline Natural Res. (24) & -2.34289 & -14.34345 & -14.34346 & -13.11417 & -10.50593 & -15.07326 & \\
\hline
\end{tabular}

Table 10 provides the $\mathrm{Z}$ scores for the seven different mutual fund categories for the ten year time horizon. In column one, the comparison is made between the mean return data of the REIT category vs. each of the other mutual fund categories. The results of this table indicate that the REIT fund category clearly outperforms all of the other mutual fund categories with the exception of Natural Resources.

\section{SUMMARY AND CONCLUSIONS}

Table 11 provides summary Data of return, standard deviation, and risk-adjusted return factors for the 1, 3, 5 , and 10 year time periods among the seven mutual fund categories analyzed in this study. A number of interesting observations can be made from Table 11. First, notice that the REIT mutual fund category outperforms both the S\&P 500 index and the Dow Jones REIT Composite Index for each of the four time periods analyzed. Even though the overall performance of the REIT funds is anything but stellar (13.8\% over ten years), the returns have been significantly better than the average for all stocks. In addition, the risk of returns, as measured by the standard deviation of returns, has also been less for the REIT category when compared to all categories for each of the four time periods.

Notice during the one year period, four categories had higher returns than the REIT category. Those included Small Value, Small Growth, Technology, and Health Care. While these categories had higher returns, they also exhibit higher standard deviations. As a result, the REIT mutual fund category outperforms all other categories on a risk-adjusted basis for the given time period of one year.

Consider the last three year time period. Notice that there were four other categories that had smaller negative returns than the REIT category. These include Small Value, Small Growth, Health Care, and Natural Resources. However because the REIT category had the smallest standard deviation of all categories, on a riskadjusted basis the REIT mutual fund category ranks second only to Natural Resources. It is interesting to note that the Natural Resources category of mutuals funds was the only category of mutual funds to experience positive gains at $.38 \%$, while all other categories were negative.

Taking a longer term perspective, consider the last five year period. Notice that only the Natural Resource category had higher returns than the REIT category. However, the REIT category had the lowest standard deviation of all categories and the second lowest risk-adjusted factor with a value of .2694. Again, the REIT category significantly outperforms the major indexes and every other mutual fund category with the exception of Natural Resources. 
Finally, consider the ten year time frame. During the last ten years the Natural Resources category returned $15.22 \%$ on average with the return of the REIT category a close second at $13.79 \%$. Again, however, the REIT category ranks first among the risk-adjusted factors, with a value of .1259.

The following conclusions can be drawn from this analysis. First, there appears to be a reasonable longterm performance record for mutual funds composed of REITs. During the ten year period, the average returns of the REIT mutual fund category ranked second to the Natural Resources category overall on a risk-adjusted basis. This is also true for the five year time horizon where the REIT mutual fund category ranked second overall on a risk-adjusted basis. Second, even in the ost recent intermediate time period of three years, the REIT mutual fund category outperforms the market indexes and again finishes second only to the Natural Resource category. Even during the most recent one year period, the REIT mutual fund category ranks first in the risk-adjusted factor.

Contrary to often conflicting return studies on REITs per se, this study indicates that REIT mutual funds have a consistent short and long-term record of performance. In fact, the REIT mutual fund category rank either first (1 year and 10 year) among the risk-adjusted performance factor, even though the average returns were not ranked first. However, it is clear from this study that REIT mutual funds have exhibited minimal volatility when measured by the standard deviation of returns. Once considered an afterthought in the financial literature, it appears that REIT mutual funds deserve a second look as a viable, stable, investment vehicle for long-term capital growth.

Table 11

Summary of Returns, Standard Deviation, and Risk-Adjusted Factors

For 1, 3, 5, and 10 Year Periods Among the Seven Mutual Fund Categories

\begin{tabular}{|c|c|c|c|c|c|c|c|c|c|c|c|c|}
\hline & \multicolumn{3}{|c|}{ One Year } & \multicolumn{3}{|c|}{ Three Year } & \multicolumn{3}{|c|}{ Five Year } & \multicolumn{3}{|c|}{ Ten Year } \\
\hline & $\begin{array}{l}\text { Average } \\
\text { Returns }\end{array}$ & $\begin{array}{l}\text { Standard } \\
\text { Deviation }\end{array}$ & $\begin{array}{c}\text { Risk- } \\
\text { Adjusted }\end{array}$ & $\begin{array}{l}\text { Average } \\
\text { Returns }\end{array}$ & $\begin{array}{l}\text { Standard } \\
\text { Deviation }\end{array}$ & $\begin{array}{c}\text { Risk- } \\
\text { Adjusted }\end{array}$ & \begin{tabular}{|l} 
Average \\
Returns
\end{tabular} & $\begin{array}{l}\text { Standard } \\
\text { Deviation }\end{array}$ & \begin{tabular}{|c|} 
Risk- \\
Adjusted
\end{tabular} & $\begin{array}{l}\text { Average } \\
\text { Returns }\end{array}$ & $\begin{array}{l}\text { Standard } \\
\text { Deviation }\end{array}$ & $\begin{array}{c}\text { Risk- } \\
\text { Adjusted }\end{array}$ \\
\hline REIT'S (66) & -37.9405 & \# 2.4501 & 甲-.0646 & -4.702 & \# 1.7946 & -0.3817 & 5.6167 & \# 1.5130 & 0.2694 & 13.7970 & 1.7367 & 0.1259 \\
\hline Large Value (50) & \begin{tabular}{|l|}
-37.9784 \\
\end{tabular} & 5.9714 & -0.1572 & -5.874 & \begin{tabular}{|l|}
2.8743 \\
\end{tabular} & -0.4893 & 1.1713 & 2.0471 & 1.7477 & 5.8472 & 2.1739 & 0.3718 \\
\hline Small Value (30) & *-22.7907 & 3.9912 & -0.1751 & $*-3.850$ & 2.1360 & -1.8024 & 4.3900 & 1.518 & 0.3458 & 11.0000 & \# 1.0601 & 0.0964 \\
\hline Small Growth (42) & $*-31.6853$ & 4.2226 & -0.1333 & $*-2.700$ & 3.0260 & -0.8923 & 1.9800 & 2.118 & 1.0697 & 8.4800 & 2.7000 & 0.3184 \\
\hline Technology (17) & $*-36.5388$ & 4.0981 & -0.1122 & -5.7241 & 3.0540 & -0.5335 & -2.8413 & 2.3473 & -0.8261 & 3.9567 & 3.6514 & 0.9228 \\
\hline Health Care (50) & $*-23.9804$ & 5.4349 & 0.2322 & $*_{-2.1578}$ & 2.7390 & -1.2693 & 3.3913 & 2.7455 & 0.8096 & 9.3721 & 1.7951 & 0.1915 \\
\hline Natural Res. (24) & \begin{tabular}{|l|}
-39.9121 \\
\end{tabular} & 8.8694 & -0.2222 & $* 0.3800$ & 2.2976 & $\vee 0.1654$ & $* 13.400$ & 2.6875 & \begin{tabular}{|l|}
0.2006 \\
\end{tabular} & $* 15.2200$ & 2.7851 & 0.1830 \\
\hline S\&P 500 & -40.2400 & & & -8.3500 & & & -2.5600 & & & 1.3800 & & \\
\hline \begin{tabular}{|l} 
DJREIT \\
Composite Index
\end{tabular} & -41.5300 & & & -16.0800 & & & -2.8100 & & & 5.9100 & & \\
\hline
\end{tabular}

* represents those mutual fund categories that delivered greater returns than the REIT mutual fund category.

\# represents those categories with the lowest standard deviation among all categories for the given time period.

$\checkmark$ indicates that category with the lowest risk-adjusted value among all categories for the given time period.

\section{AUTHOR INFORMATION}

Dr. James L. Kuhle is currently Professor of Finance at California State University, Sacramento, Ca., USA. Dr. Kuhle completed his PhD in Finance from The University of Texas, Austin, Texas. He earned his MBA in Finance from the University of California, Los Angeles, USA. Dr. Kuhle has published numerous articles in national and international journals in the area of investment analysis and real estate investment.

Dr. Rafiqul Bhuyan Rafiq (aka Rafiqul Bhuyan) is an Associate Professor of Finance at California State University San Bernardino, Ca. USA. Dr. Rafiq completed his PhD from Concordia University, Montreal, Canada. He earned his M.Sc. in Finance from the University of Illinois at Urbana-Champaign, USA. Dr. Rafiq has published numerous articles in national and international journals and served as discussant and reviewers in academic conferences and journals respectively.

\section{REFERENCES}

1. Carhart, M., On Persistence in Mutual Fund Performance, The Journal of Finance, 1997, 52, 57-82. 
2. Chan, K. C., P. H. Hendershott and A. B. Sanders, Risk and Return on Real Estate: Evidence from Equity REITs, Journal of the American Real Estate and Urban Economics Association, 1990, 18, 431-52.

3. Elton, E. J., M. J. Gruber, S. Das and M. Hlavka, Efficiency with Costly Information: A Reinterpretation of Evidence from Managed Portfolios, Review of Financial Studies, 1993, 6, 122.

4. $\quad$ Elton, E. J., M. J. Gruber, S. Das and C. R. Blake, The Persistence of Risk-Adjusted Mutual Fund Performance, Journal of Business, 1996, 69, 133-57.

5. Glascock, J. L., Market Conditions, Risk and Real Estate Portfolio Returns: Some Empirical Evidence, Journal of Real Estate Finance and Economics, 1991, 4, 367-73.

6. Goebel, P. R. and K S. Kim, Performance Evaluation of Finite-- Life Real Estate Investment Trusts, Journal of Real Estate Research, 1989, 4, 57-69.

7. Jensen, M., The Performance of Mutual Funds in the Period 1945-64, Journal of Finance, 1968, 23, 389416.

8. Kallberg, Jarl G., Liu Crocker L., and Charles Trzcinka, The Value Added from Investment Managers: An Examination of Funds of REITs, Journal of Financial and Quantitative Analysis, Vol. 35, 3, 387-409.

9. Kuhle, J. L., C. H. Walther and C. H. Wurtzebach, Financial Performance of Real Estate Investment Trusts, Journal of Real Estate Research, 1986, 1:1, 67-75.

10. Lin, Crystal Yan, and Kenneth Yung, Real Estate Mutual Funds: a Style Analysis, Financial Services Review, 2007, Volume 16, Issue 4, 261-274.

11. Martin, J. D. and D. 0. Cook, A Comparison of the Recent Performance of Publicly Traded Real Property Portfolios and Common Stock, Journal of the American Real Estate and Urban Economics Association, 1991, 19, 184-212.

12. Redding, Lee S., Persistent Mispricing in Mutual Funds: The Case of Real Estate, Journal of Real Estate Portfolio Management, 2006, Vol. 12, Issue 3, 223-233.

13. Titman, S. and A. Warga, Risk and the Performance of Real Estate Investment Trusts: A Multiple Index Approach, Journal of the American Real Estate and Urban Economics Association, 1986, 14, 414-31.

14. Webb, J. R. and F. C. Neil Myer, Management Style and Asset Allocations in Real Estate Portfolios, Journal of Real Estate Portfolio Management, 1996, 2, 119-25. 